\title{
Os trabalhos e os dias, de Baltazar Lopes: a visão mítico-cosmogônica de um povo
}

\author{
RosÂNGeLA SARTESCHI \\ Universidade de São Paulo
}

RESUMO: A PARTIR DO EXAME DE MITOS, ELABORA-SE UMA LEITURA COMPARATIVA ENTRE O CANTO O TRABALHOS E OS DIAS DO POETA GREGO HESÍODO, E O CONTO DO AUTOR CABOVERDIANO BALTAZAR LOPES.

ABSTRACT: BASED ON THE EXAMINATION OF MYTHS, A COMPARATIVE READING BETWEEN THE CHANT OS TRABALHOS E OS DIAS, BY THE GRECIAN POET HESÍODO, AND THE SHORT-STORY BY THE CAPE VERDIAN AUTHOR BALTAZAR LOPES IS ELABORATED.

PALAVRAS-CHAVE: LITERATURA CABOVERDIANA, HESÍODO, BALTAZAR LOPES, OS TRABALHOS E OS DIAS.

KEY-WORDS: CAPE VERDIAN LITERATURE, HESÍODO, BALTAZAR LOPES, OS TRABALHOS E OS DIAS. 
ste trabalho resulta de uma reflexão sobre o conto Os trabalhos e os dias, de Baltazar Lopes, relacionado com o longo canto homônimo de Hesíodo, o poeta grego que viveu na Beócia provavelmente no final do século VIII A.C. Para tanto, concentramos nossa interpretação na primeira parte (versos 1-382) d'Os trabalhos e os dias, de Hesíodo por considerar que ali apresentam-se vários mitos que reaparecem transformados no conto cabo-verdiano.

O objetivo é trilhar um caminho interpretativo diverso daqueles seguidos até agora pelos estudiosos da obra ficcional do autor cabo-verdiano. Evidentemente não se trata de negar aqui os índices neo-realistas do conto, como bem ressaltou Armênio Vieira no prefácio do livro: "Os trabalhos e os dias, o qual, curiosamente, é aquele que, tanto pelo tema como pela massa de figurantes que põe em movimento, mais se aproxima da narrativa de intenção neo-realista" (LOPES, 1986, p. 12). Trata-se de uma tentativa de ampliar as possibilidades de interpretação que as obras de ficção comportam, redimensionando-as e conferindo-lhes um caráter universalizante.

Nesse sentido, parece-nos bastante pertinente examinar como os mitos da obra de Hesíodo se reelaboram na do escritor cabo-verdiano, ressurgindo, por vezes confirmados, por vezes subvertidos com a clara finalidade, parece-nos, de integrá-los à "realidade" que é a do seu Os trabalhos e os dias. Essa aproximação acaba por constituir-se, assim, em mais do que o resultado de uma simples releitura do original grego: torna-se uma recriação daquele universo africano.

À primeira vista, a tentativa de vislumbrar, em um conto de reconhecível marca neo-realista, a presença de mitos gregos, mais concertados com fábulas ou contos maravilhosos, poderá causar certo estranhamento. No entanto, esse viés interpretativo não se configura como um contra-senso, pois como afirma N. Frye em sua Anatomia da Critica:

"O realismo, ou a arte da verossimilhança, evoca a reação: "Como isto é parecido com o que conhecemos!” Quando o que está escrito é como o que se conhece, temos uma arte do símile extensivo ou subentendido. E assim como o realismo é uma arte o símile implícito, o mito é uma arte de identidade metafórica implícita [...] No mito vemos isolados os princípios estruturais da literatura, no realismo vemos os mesmos princípios estruturais (não princípios semelhantes) ajustando-se a um contexto de plausibilidade" (FRYE, s/d, p. 138). 
Para o crítico canadense, o mito é um extremo da invenção literária; o naturalismo é o outro e entre ambos estende-se a história romanesca, tomando como ponto de partida o deslocamento do mito em uma direção humana, e todavia, em contraste com o "realismo", preserva da convenção do conteúdo um viés idealizado:

“O princípio fundamental da deslocação é este: o que pode ser identificado metaforicamente num mito pode apenas ser vinculado, na estória romanesca, por alguma forma de símile: analogia, associação significativa, imagem incidental agregada, e semelhantes. No mito podemos ter um deus-Sol ou deus-árvore; numa estória romanesca, uma pessoa significativamente associada com o sol ou as árvores. Nos modos mais realísticos, a associação se torna menos significativa e mais uma caso de imagens incidentais, e mesmo coincidentes ou fortuitas." (FRYE, s/d, p. 139).

No âmbito dessa mesma questão, para M. Eliade o mito é a narrativa de uma criação e sua principal função consiste em revelar modelos exemplares dos ritos significativos da humanidade referentes, por exemplo, à alimentação, ao casamento, à educação, à arte, à sabedoria e ao trabalho.

Dessa maneira,

"o mito, portanto, é um ingrediente vital da civilização humana; longe de ser uma fabulação vã, ele é ao contrário uma realidade viva, à qual se recorre incessantemente; não é absolutamente uma teoria abstrata ou uma fantasia artística, mas uma verdadeira codificação da religião primitiva e da sabedoria prática." (ELIADE, 1986, p. 23).

Sendo assim, ler o conto do escritor cabo-verdiano à luz de mitos gregos possibilita levantar questões no espaço do debate crítico-literário, que apontam para as raízes de um povo ainda oprimido sob o jugo colonialista português. Vislumbra-se aqui o mito de origem da nação cabo-verdiana.

À guisa de uma exegese, cabe questionar: do que trata afinal o canto Os trabalhos e os dias, de Hesíodo? 
“O próprio título da segunda obra de Hesíodo nos faz pensar em um poema didático cuja finalidade é ensinar os trabalhos da terra, apontar as épocas em que é conveniente empreendê-los. Por certo, os conselhos dirigidos ao agricultor e ao navegante dão aos Trabalhos e Dias êsse aspecto didático, mas esse poema não se resume nisso.”, diz Aubreton. (1956, p. 25).

Para M. Lafer, os temas centrais desse longo poema são resumidamente: a origem do homem, a origem dos males, a necessidade do trabalho e da justiça.

Será, portanto, a partir desses dois pontos de vista - complementares entre si - acerca do poema grego que traçaremos o paralelo com o texto caboverdiano.

A primeira questão que se coloca diz respeito aos dois autores. Como sabemos, Baltazar Lopes é escritor fortemente ligado à revista Claridade, que reuniu intelectuais (poetas e ficcionistas) cujas obras refletiam suas preocupações não apenas estéticas, mas também sociais e políticas. São temas recorrentes dos autores, e em especial do aqui enfocado, as próprias condições do arquipélago: a insularidade, o flagelo da seca, a crise econômica, o colonialismo e a busca de uma identidade nacional que então se iniciava.

Também, ao contrário de Homero que cantava a vida dos senhores, suas festas e suas guerras, Hesíodo fala-nos de forma nada idealizada acerca da dura vida dos camponeses. O poeta grego fala de seu próprio trabalho, o de agricultores e dirige-se a destinatários bem determinados: seu irmão Perses, pequenos agricultores e, eventualmente, poderosos proprietários de terra. Por meio de seu canto, reivindica uma "prática jurídica inspirada na justiça de Zeus" (LAFER, 1991, p. 16). Não seria exagero, então, deduzir que ele constitui-se, em certa medida, no porta-voz dos oprimidos.

Vemos, portanto, que em ambos apresenta-se nova postura diante da própria função poética/artística quanto ao objeto da criação literária e ainda quanto ao público a que pretendem destinar-se. De certa maneira, Hesíodo e Baltazar Lopes rompem com "cânone" estabelecido, ensejando, com isso, uma forma de arte com mais compromissos diante do homem comum.

Cabe-nos, nessa instância, colocar a seguinte questão: por que Baltazar Lopes adotou, não só para o conto objeto dessa análise mas também para o livro no qual ele está inserido, o nome de um clássico poema grego tão distante - em princípio - do seu universo? 
$\mathrm{Na}$ verdade, há uma relação do estreito e contínuo diálogo que se coloca entre as duas criações literárias, como é a que resulta da intertextualidade a que se referia J. Kristeva a partir dos conceitos bakhtinianos.

Vale lembrar, também, que esse encontro cultural demonstra que "o discurso não se constrói sobre o mesmo mas se elabora em vista do outro. Em outras palavras, o outro perpassa, atravessa, condiciona o discurso do eu" (BAKHTIN, 1988, p. 127) e o resultado final é a construção eficiente de sentidos: o universo que se cria a partir das possibilidades tanto do escritor/criador como, afinal, também do leitor, que passa, assim, a figurar como agente desse processo.

Assim, recuperar essa ligação, que não nos parece meramente casual, é essencial para o alargamento do universo de significações da obra cabo-verdiana.

Outro ponto a destacar refere-se ao fato de que ambos os textos fazem parte de culturas de larga tradição oral e ágrafa. Nesse sentido, o narrador assume destacada importância, na medida em que é responsável pela transmissão das histórias fundadoras de seu povo. É o contar e recontar repetidos que garantem a existência do ser. Ao narrador está ligada, portanto, a idéia da rememoração como ato simbólico vital à humanidade.

Segundo W. Benjamin, o narrador retira da experiência própria ou da relatada por terceiros o que ele conta e incorpora às coisas narradas da experiência dos seus ouvintes. Nessas culturas, a existência se dá fundamentalmente através do contato e da troca. Para o ensaísta, o narrador é, afinal, o homem intimamente ligado à noção de sabedoria e que, por isso, dá conselhos, que são tecidos na substância viva da existência.

O texto grego é o canto das Musas, um hino à glória, ao poder e à justiça de Zeus, mas também é um canto de louvor ao trabalho. O cantor é nomeadamente o próprio Hesíodo, como vemos em:

“Tu! Eu a Perses verdades quero contar.” (HESÍODO, v.10)

"Se queres, com outra estória esta encimarei," (HESÍODO, v. 106)

Já no conto de Baltazar Lopes, elaborado em terceira pessoa, é a figura do narrador que assume, ainda que implicitamente, o papel de trazer à luz a história daqueles homens desaventurados.

A opção por esse ponto de vista talvez se deva a marcar o texto com o crivo da objetividade e de criar um certo distanciamento dos eventos narrados. 
No entanto, a figura de Nhô Manuel Antoninho assume o papel que cabia ao narrador: é ele a personagem que detém a sabedoria (ligada à experiência) além de um profundo senso de justiça, que, por isso mesmo, torna-o merecedor do respeito daqueles que estão a seu redor: "E que Delfim sabe que Nhô Manuel dá exemplo e lição aos rapazes novos" (LOPES, 1987, 77).

É ele o detentor da memória que tem sua deusa na tradição e cultura gregas. Ao narrador compete, como vimos, contar e recontar acontecimentos, transmitindo de geração em geração as suas "reminiscências". A memória é, assim, musa da poesia épica e da narrativa.

No momento em que Nhô Manuel Antoninho passa a ser o narrador dentro da história, vê-se claramente serem a ele confiadas a memória e a sabedoria:

"Todos delegavam na sua capacidade militante de narrar o encargo de aliviar a caminhada. Que importa que já soubessem de cor e salteado o seu repertório?” (LOPES, 1987, p. 80)

Assim como em Hesíodo, cabe a ele a responsabilidade de contar as façanhas de seu povo a fim de preservar a sua vitalidade. Não é por acaso que, segundo W. Benjamin, a narrativa tenha florescido em meio de artesãos (no campo, no mar, nas cidades), constituindo-se ela própria, em certa medida, uma forma artesanal de comunicação. A narrativa "não está interessada em transmitir o puro em si' da coisa narrada como uma informação ou um relatório. Ela mergulha a coisa na vida do narrador para em seguida retirá-la dele." (Benjamin, 1985, p. 205)

Cabe-nos, agora, destacar que no conto de Baltazar Lopes reaparece a noção de desmedida (býbris) e de justiça (dike), presentes no texto grego.

Para Hesíodo, a noção de justiça deve sempre prevalecer sobre todas as coisas e, para que isso ocorra, cumpre atentar para a noção de medida: o excesso leva à queda inexorável:

"Guarda a medida: o propósito é em tudo a qualidade suprema." (HESÍODO, v. 694)

Nas cinco raças por ele relatadas (ouro, prata, bronze, ferro e entre as duas últimas coloca-se a raça dos heróis), sempre houve confronto entre díke e býbris: todo o canto grego se estabelece a partir da tensão dialética entre as 
duas noções, que se apresentam ao homem como duas opções igualmente possíveis entre as quais se faz necessária a escolha. Hesíodo deixa claro que a decadência das raças (simbolizada pelos metais que serviram para nomeálas) deu-se na medida em que a býbris paulatinamente triunfou sobre a díke. $\mathrm{O}$ universo, então, transformou-se; tornou-se caótico e confuso, onde subsistem, conforme registra o depoimento seguinte:

"apenas desordem e desgraças em estado puro [...] Assim, o mito parece querer opor a um mundo divino, em que a ordem é inevitavelmente fixada desde a vitória de Zeus, em um mundo humano no qual a desordem se instala pouco a pouco e que deve acabar virando inteiramente para o lado da injustiça, da desgraça e da morte." (VERNANT, 1990, p. 31).

Hesíodo tenta, assim, demonstrar a seu irmão Perses e aos poderosos reis as virtudes da díke e os perigos da hýbris, lembrando-os de que há seres superiores dos quais dependem e aos quais devem prestar contas:

"Isto observando, alinhai as palavras, ó reis comedores-de-presentes, esquecei de vez tortas sentenças! A si mesmo o homem faz mal, a um outro o mal fazendo: para quem a intenta a má intenção malíssima é.” (HESÍODO, vv. 263-266)

No conto cabo-verdiano, o apelo à justiça é naquele universo desordenado e caótico em que transitam as personagens, pertencentes à raça de ferro preconizada pelo poeta grego:

"Pois agora é a raça de ferro e nunca durante o dia cessarão de labutar e penar e nem à noite de se destruir; e árduas angústias os deuses lhe darão.” (HESÏODO, vv. 176-178)

E esse apelo vem pela voz da personagem Nhô Manuel, que, como vimos, encerra em si a sabedoria ancestral que foi confiada pelos antepassados, conferindo-lhe autoridade moral para que afronte as autoridades constituídas: 
“O milho não era do guarda. O milho, quem deu foi Nossenhor [...] O guarda não queria usar a pistola para fazer respeitar a autoridade.” (LOPES, 1987, p. 82)

"-Quem é que lhe deu estas ordens de tirar o sustento da boca dos coitadinhos? [...] Tire a mão dessa arma do Diabo, desgraçado. Vossemecê nada pode fazer contra a justiça de Nosso Senhor Jesus Cristo.” (LOPES, 1987, p. 83)

O apelo para que se ouça a justiça, para que se deixe de lado a desmedida é, em última análise, o clamor da voz cansada do povo subjugado pelo colonizador.

Nhô Manuel Antoninho tenta fazer com que o guarda - representante do poder estabelecido, do status quo - compreenda que se a justiça (dikee) for vencida pela desmedida (býbris) aquele universo tornar-se-á ainda mais desordenado, onde paira a ameaça de eternizarem-se a miséria, o sofrimento, doenças e mortes. E suas palavras não são menos rudes e duras do que as de Hesíodo foram.

É nesse ponto que se pode ampliar o paralelo entre as duas obras: tanto em Hesíodo quanto em Baltazar Lopes fica claro que ao homem é dado o poder da escolha, mas que convém sempre respeitar as leis e a justiça pelas quais se assegura o direito de todos o homens.

Se na visão de Hesíodo do mito de Prometeu e Pandora, foi Zeus quem mandou todos os males para os homens, males esses "que se tornaram inseparáveis da condição humana” (VERNANT, 1990, p. 25), no conto de Baltazar Lopes, no entanto, os males que se tornaram agregados à condição do homem são, sobretudo, o resultado dos desmandos (a býbris presente mais uma vez) e da violência decorrentes do processo de colonização, como bem notou A. Carvalho:

"o europeu, representado por uma minoria insignificante, usou do dinamismo de sua cultura e dominou o africano, a despeito da importância numérica desse [...] era a força advinda da detenção de melhores 'armas' e maior argúcia [...] a superioridade da cultura, oferece um bom ponto de partida, na condição de reduzirmos previamente as metáforas do 'poder' (dominou o africano) e da 'especialidade' valorativa (superioridade vs inferioridade cultural)" (CARVALHO, 1986, p. 32)

A ordem e a harmonia só serão restabelecidas pela imprevista intervenção da providência divina: o milho que aparece em conseqüência do encalhe do navio, para suprir necessidades básicas de sobrevivência. 
Nesse sentido, devemos, então, apontar para a forma notável de como os dois textos são trespassados pela força mítica como determinante no destino do homem.

Em Os trabalhos e os dias, de Hesíodo, todos os deuses giram ao redor do supremo Zeus, cuja onisciência e onipresença se irradiam sobre todo o poema:

"O olhos de Zeus que tudo vê e assim tudo sabe também isto vê, se quiser, vê e não ignora” (HESÏODO, vv. 267-268)

“Zeus altissonante que altíssimos palácios habita.”(HESÏODO, v. 8)

É Zeus quem estabelece a justiça, distribuindo o bem ou gerando males e destruição aos seres humanos. Dessa forma, o poeta sugere o respeito às leis divinas, pois a infração leva certamente à punição. Não se pode nunca desprezar a díke: essa é a lei suprema.

No texto do escritor cabo-verdiano o misticismo também está presente:

“- São ordens, velhote. Móia é coisa antiga, já acabou...

- Não acabou nada. Para acabar era preciso que também tivesse acabado Nosso Senhor Jesus Cristo, que deixou esta esmola ao povo.” (LOPES, 1987, p. 83)

Como vemos, há, nesse texto, também, o apelo para a observância dos desígnios divinos, pois eles implicam, na verdade, em respeito ao cumprimento da justiça (díke). Ainda uma vez é Nhô Manuel quem alerta para a ordem das leis supremas:

“- Vossemecê tira-me daqui, se é capaz de faltar ao respeito devido à palavra de um velho.

$[\ldots]$

- Fique vossemecê sabendo que Deus Nosso Senhor Jesus Cristo é que manda acima de todos os mandões do planeta Terra.” (LOPES, 1987, p. 83)

Ressalte-se, ainda, que esta obediência às leis superiores e, por conseguinte, $\mathrm{o}$ respeito à díke, encontra terreno propício na própria índole do cabo-verdiano, 
conforme afirma Alberto Carvalho: "é intrínseco o seu sentido de respeito e obediência às instituições e poder." (CARVALHO, 1986, p. 32).

A outra questão que ambos os autores contemplam, ainda que de maneira diversa, é o trabalho. Quanto a Hesíodo,

"o trabalho é a base da justiça entre os homens, sem um não há outra... Para ele a defesa e a reiteração da necessidade do trabalho se fazem por motivos ligados à sobrevivência material...” (LAFER, 1991, p. 57).

Acrescente-se a esse, outro parecer de que Os trabalhos e os dias, de Hesíodo consiste no "primeiro bino ao trabalho" (VERNANT, 1990, p. 261).

Não podemos deixar de notar que, na obra do escritor grego, os seres humanos são destinados ao trabalho por vontade de Zeus e, portanto, devem aceitar a lei divina e não poupar esforços para cumpri-la. Com a decadência das raças, o trabalho torna-se necessário para a obtenção dos dons da terra; os alimentos não mais estão à disposição dos homens como nas raças anteriores; os homens da raça de ferro têm que lutar muito por sua sobrevivência.

Nesse sentido, o trabalho glorificado é o trabalho da terra e a relação do homem e o trabalho da terra é estritamente religiosa, pois é:

"através de seu esforço e de sua fadiga, que o homem entra em contato com as forças divinas... A Terra, sendo uma divindade, ensina a justiça aos que são capazes de aprendê-la." (VERNANT, 1990, pp.262-265).

Vemos, portanto, que para Hesíodo a riqueza não é dádiva divina, mas fruto do trabalho que, ao exigir disciplina, requer medida; não respeitá-la significa ir ao encontro dos nefastos efeitos da býbris.

Em Baltazar Lopes, porém, essa mítica aparece transformada. Tem-se a sugestão de que o mito grego está na base de uma concepção que, entretanto, se traduz caboverdianamente na forma de que o trabalho não é fonte de justiça, "nem 'dever', nem 'obrigação', o trabalho deveria ser entendido como 'tributo' social justificado pela lei natural.", como entendeu A. Carvalho (1986, p. 55).

Verdade é que o isolamento das ilhas devido à fragmentação espacial bem como a diversidade do relevo dificultam o desenvolvimento, mas é, sobretudo, pela interferência indébita do colonizador que o trabalho não logra resultar em 
fartura e riqueza. Assim sendo, a plenitude da comunhão religiosa homemnatureza do mundo grego não se repete no universo cabo-verdiano. Muitas vezes a natureza parece até conspirar contra o homem do campo:

"Os homens atacam o lajedo, estendido apenas dois palmos debaixo da terra arável. Nhô Manuel não consegue abater o bocado de lajedo que competia à sua enxada? Ela cai, vai caindo, mas a rocha resiste.” (LOPES, 1987, p. 77)

Pode-se deduzir que em seu texto, Baltazar Lopes acena para um futuro onde o homem espoliado pelo poder colonial poderá esperar que a justiça - fonte da prosperidade, que, por sua vez, é recompensa do trabalho - se cumpra como predição divina:

"Era uma história de outro tempo, mais feliz, mais de homem, que nestes anos tão fracos parecia vir de um mundo morto para todo o sempre. Mas quem sabe se amanhã, quando Deus se cansasse de experimentar a suas criaturas, não viria finalmente um tempo assim, em que a enxada não signifique que há noites sem ceia, cachupa só de água e sal, e esta grande desgraça de um cristão não ter um minuto de seu, que não seja desmesuradamente coberto pelo preço do litro de milho branco de Angola nas lojas do Porto!" (LOPES, 1987, p. 80)

A intervenção divina dos gregos do "Zeus que tudo vê" é que vai se transcodificar em justiça aos cabo-verdianos. É Deus, que, em desacordo com tal injustiça, intervém, através do navio encalhado, para fazer chegar o alimento ao povo cujo trabalho é sem recompensa. No entanto, essa postura será alterada, como veremos adiante.

Em outro ponto, porém, parece haver coincidência com o texto clássico, a de que o agricultor é visto como guerreiro, pois a agricultura é uma luta que exige coragem por sua própria natureza; requer que não se temam as canseiras nem se poupem as forças, sem as quais ela não gratificará com sucesso:

"João Conceição dá uma ajuda ao velho e a enxada de Nhô Manuel torna a cair corajosamente sobre a terra do lajedo.” (LOPES, 1987, p. 77) 
Cabe relevar, ainda, como o milho assume o valor simbólico de prosperidade, em determinadas culturas. Para civilizações peruanas, por exemplo, a idéia de fertilidade pode ser formatizada em uma figura elaborada com talos dessa planta americana, como mulher, a qual denominam mãe do milho.

É ao encontro desse milho que correntes de imigrantes, inclusive caboverdianos, também vão para, quem sabe, "fazer a América" uma designação como a do enigmático navio encalhado no porto de Cabo Verde.

Devemos destacar, finalmente, o herói trágico, que embora não apareça especificamente no texto grego aqui enfocado, é herói muito caro a toda a tradição na cultura da Grécia.

Em Nhô Manuel Antoninho essa figura revive, ele personifica, em certa medida, o herói trágico. De acordo com N. Frye, essa categoria está entre o divino e o humano. No mito, o herói é um deus e, por isso, ao morrer, ressurge para a vida.

Quando Nhô Manuel desafia a lei estabelecida, liberta-se do jugo da ordem imposta, transformando-se em um novo homem, é como morrer para renascer. Passa, com isso, a ser sujeito de sua própria história, na direção de construir uma nova ordem social. Ao defrontar-se com o policial, Nhô Manuel atinge o momento crucial (Augenblick, na concepção de Frye), de epifania, de onde pode vislumbrar "a estrada para o que poderia ter sido e a estrada para o que será." (FRYE, s/d, p. 210).

Esse momento, portanto, pode ser entendido de duas maneiras: por um lado, é o do reconhecimento do homem enquanto agente modificador de seu destino (a anagnórisis para os gregos); por outro lado, é o do restabelecimento ainda que talvez momentâneo - de um equilíbrio há muito perdido e resgatado, então, pelo herói com arrojo e paixão.

Para finalizar esta reflexão, tomamos as palavras de M. Lafer, sobre a obra de Hesíodo: "os 382 versos iniciais constituem-se numa espécie de arcabouço mítico-cosmogônico para a segunda parte do poema." (1991, p.15)

Pois o conto de Baltazar Lopes, em sua quarta e última parte, sugere, também, uma cosmogonia. Aquele mundo destruído, de alguma forma se recria e um novo é criado (não se sabe, é certo, até quando). A ordem estabelecida foi quebrada. Ao enfrentar o guarda, Nhô Manuel - e com ele as demais personagens - começa vida nova, com outra ordem, mais próxima da díke grega. 
Na atitude de Nhô Manuel Antoninho, há uma tentativa de volta às origens, a tempos bem longínquos muito anteriores à colonização. Esse retorno às origens encerra, segundo M. Eliade, "a esperança de um renascimento” (ELIADE, 1986, p. 33).

As palavras de Nhô Manuel têm força criadora, pois correspondem ao pensamento de que "tudo que o homem faz repete, de certa forma, o feito por excelência, o gesto arquetípico do Deus criador: a Criação do Mundo.” (ELIADE, 1986, p. 34)

"Em silêncio, todos foram com o milho para a Triste Fera. Sozinho, no Lajedo, o guarda apitou ao vapor, para lhe trazerem o bote.”(LOPES, 1987, p. 83)

Entendemos, portanto, que, no conto de Baltazar Lopes, a simbolização é o da trajetória concisa de um povo - da opressão à libertação. O fio condutor dessa trajetória não é outro senão o que busca as origens de um povo até então aparentemente "adormecido". No conto Os trabalhos e os dias, a narrativa apela, portanto, em última instância, para a cosmogonia, para as forças renascedoras primordiais do universo cabo-verdiano.

\section{Referências bibliográficas:}

HESÍODO. Os trabalhos e os dias-primeira parte. Tradução e notas de Mary de Camargo Neves Lafer. São Paulo: Ed. Iluminuras, 1991.

LOPES, B. Os trabalhos e dos dias. Alac África: Literatura, Arte e Cultura, 1987.

AUBRETON, R. Introdução a Hesíodo. São Paulo: Universidade de São Paulo, FFLCH, Boletim 215, 1956.

BAKHTIN, M. Questões de Literatura e de estética. A teoria do romance. São Paulo: Hucitec/ UNESP, 1988.

BENJAMIN, W. Magia e técnica. Artes e política: ensaio sobre literatura e história da cultura. São Paulo: Ed. Brasiliense, 1985.

CARVALHO, A. D. A ficção de Baltazar Lopes: contributo para a originalidade da literatura cabo-verdiana. LISBOA, 1986 (tese de doutoramento)

ELIADE, M. Mito e realidade. São Paulo: Ed. Perspectiva, 1986.

FRYE, N. Anatomia da Crítica. São Paulo: Ed. Cultrix. s/d.

VERNANT, J. P. Mito e pensamento entre os gregos. São Paulo: Ed. Paz e Terra, 1990. 